\title{
Factors Influencing Male Reproductive Success in a Cryptomeria japonica Seed Orchard Revealed by Microsatellite Marker Analysis
}

\author{
By Y. Moriguchi ${ }^{1)}$, S. TsuchiYa ${ }^{1)}$, H. Iwata ${ }^{2)}$, S. Itoo $^{3)}$, N. TAni $^{4)}$, H. TAIrA $^{1)}$ and Y. Tsumura ${ }^{4), *)}$
}

(Received 23 ${ }^{\text {th }}$ March 2006)

\begin{abstract}
We investigated the influence of male flower production, floral synchrony and inter-tree distances on male reproductive success in a miniature seed orchard of Cryptomeria japonica. We used six microsatellite markers to determine the paternity of each seed. In the seed orchard, the average pollen contamination and clonal self-fertilization rates were $38.7 \%$ and $1.7 \%$, respectively. The level of male reproductive success of constituent clones varied from 0.0 to $15.7 \%$. Five clones showing the highest male reproductive success contributed ca. $30 \%$ of all analyzed seeds as a pollen donor after excluding contamination by external sources of pollen. The statistical analyses showed that male reproductive success was strongly influenced by male flower production of each clone and, possibly, by their distance to the mother trees. The linear regression which included male flower production and floral synchrony as independent variables, however, accounted for only $14.7 \%$ of variation of male reproductive success, suggesting that other factors such as pollen competition might also influence male reproductive success. Since we found no significant correlation between male reproductive and female reproductive successes, it may be better to equalize male and female reproductive successes independently.
\end{abstract}

Key words: conifer, floral phenology, paternal contribution, SSR.

\section{Introduction}

Seed orchards, which consist of superior tree clones, are important sources of materials for afforestation. Ideally, such materials should have high genetic value and diversity. In order to maintain high genetic value of their seeds, rates of contamination by external pollen and self-fertilization within the orchards should be minimal, while the male reproductive success of the constituent clones should be roughly equal to ensure the seeds have high diversity.

Recently, many studies have assessed the quality of seed yields using molecular markers. Pollen contamination rates exceeding $30 \%$ have been found in most seed orchards of dominant forestry species (WHEELER and

\footnotetext{
1) Korea Forest Research Institute, 44-3 Omokchon-dong, Kwonsun-ku, Suwon, Gyeonggi-do, 441-350, Republic of Korea.

2) Department of Information Science and Technology, National Agricultural Research Center, 3-1-1 Kannondai, Tsukuba, Ibaraki 305-8666, Japan.

3) Niigata Prefectural Forest Research Institute, Asahi-mura, Iwafune-gun, Niigata 958-02, Japan.

4) Department of Forest Genetics, Forestry and Forest Products Research Institute, 1 Matsunosato, Tsukuba, Ibaraki 305-8687, Japan.

*) Corresponding author: Yoshiniko TsumuRA, Department of Forest Genetics, Forestry and Forest Products Research Institute, Tsukuba, Ibaraki 305-8687, Japan. Tel. +81-29-826-8261; Fax +81-29-874-3720; E-mail: ytsumu@ffpri.affrc.go.jp
}

JECH, 1992 for review; ADAMs et al., 1997; STOEHR et al., 1998; PAKKANEN et al., 2000; MoRiguchi et al., 2004, 2005), and self-fertilization rates appear to be around $5 \%$ in most seed orchards examined to date (RITLAND and El-KassabY, 1985; RUdin et al., 1986; Goto et al., 2002; MoRiguchi et al., 2004, 2005). Furthermore, male reproductive success has deviated from equality in all studies in which it has been examined (STOEHR et al., 1998; Goto et al., 2002; Stoehr and Newton, 2002; MoRIGUCHI et al., 2004, 2005). These findings suggest that the quality and diversity of seeds in seed orchards may be affected by multiple factors, and several such factors have been identified. First, various authors have proposed that the pollen contamination rate among ramets within seed orchards may be related to their spatial distance from neighboring artificial forests (FRIEDMAN and ADAMS, 1985; YAZDANI and LINDGREN, 1991; MoriguchI et al., 2004). Second, the average contamination rate of seed orchards is influenced by the area of surrounding artificial forests (MORIGUCHI et al., 2005). Third, differences in self-fertization rates of ramets within a seed orchard are related to the temporal separation of seed cone receptivity and pollen shed within clones (STOEHR et al., 1998), the amounts of pollen produced (ScHOEN et al., 1986), and variations in both spacing and crown size (RITLAND and EL-KASSABY, 1985; PAKKANEN et al., 2000). Fourth, the average self-fertilization rate within seed orchards is influenced by the number of ramets per constituent clone (MORIGUCHI et al., 2005). However, there have been few studies on factors that influence male reproductive success, because previously used genetic markers such as allozymes provide insufficient resolution to determine the pollen donors of the progeny, due to the small number of allozyme loci available for analysis and their low polymorphism.

Therefore, in the present study, we used microsatellite markers to investigate pollen-mediated gene flow in a Cryptomeria japonica seed orchard. Microsatellite markers are powerful molecular tools for determining parentage due to the high levels of variation in the repeat units. Our objective was to assess the relationships between the male reproductive success of all constituent clones and biological traits such as male flower production, floral synchrony and inter-tree distances. The results of such studies could be used to further improve seed orchards.

\section{Materials and Methods \\ Investigated seed orchard}

This study was carried out in a miniature seed orchard in Niigata Prefecture $\left(37^{\circ} 34^{\prime} \mathrm{N}, 1^{\circ} 38^{\circ} 46^{\prime} \mathrm{E}\right)$. The 
height of the trees of each clone was about $2 \mathrm{~m}$, they were spaced $1.5 \times 1.5 \mathrm{~m}$ apart, and the orchard was 15 years old. The orchard covers 2.8 ha and was divided into 26 blocks. Gibberellin was applied to a study block ( 0.10 ha) containing 1144 trees $(11,555 / \mathrm{ha})$ representing 54 clones to induce the flowering of seed trees at the end of July 1999. Data on biological parameters such as male flower production and flowering phenology in this miniature seed orchard were collected in the flowering season of the year 2000 .

\section{Airborne pollen survey}

Airborne C. japonica pollen was collected $1.3 \mathrm{~m}$ above the ground by Durham samplers (DURHAM, 1946) at two observation points, one $300 \mathrm{~m}$ north of the orchard (outside the seed orchard) and one in the center of the gibberellin-treated study block (Figure 1). The pollen was collected from 7 March to 11 April. A glass slide smeared with petrolatum was collected every day at 9:00 AM, and the pollen grains within a $1 \mathrm{~cm} \times 1 \mathrm{~cm}$ area on the slide were counted under a microscope at x 200 magnification. Daily airborne pollen counts were expressed as counts $/ \mathrm{cm}^{2}$.

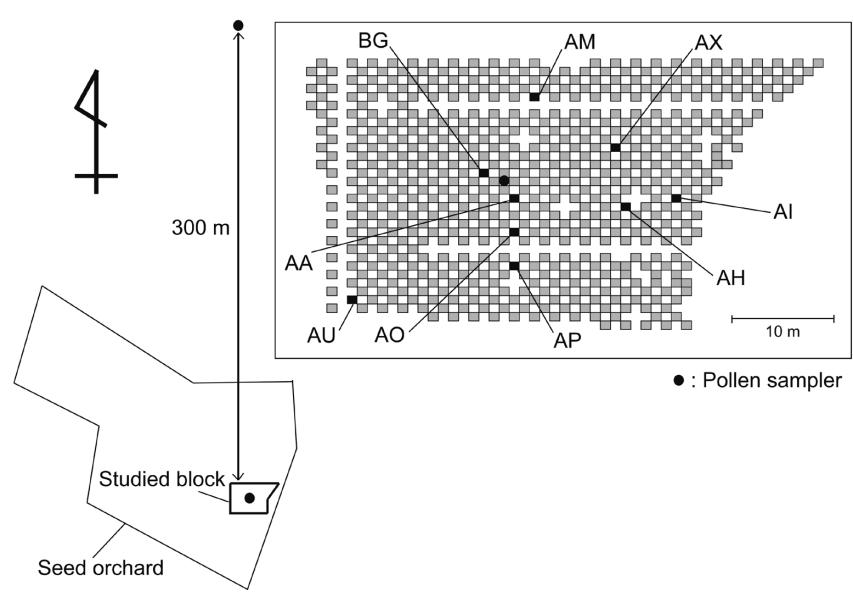

Figure 1. - Location of the nine mother trees in studied block and pollen samplers (black circles).

\section{Male flower production}

First, the amount of male flowers on each ramet was visually graded in the following five classes: (0) none, (1) very few, (2) light, (3) medium, and (4) high. Second, the quantity of male flowers on a single ramet was estimated for each specific class by random sampling measurements. That is, we randomly sampled three ramets from each class, and measured the total weight of male flowers on the single ramet after drying at $105^{\circ} \mathrm{C}$ for three days. Then, male flower production of a single ramet was estimated for each class as the average weight of these three ramets. Finally, male flower production of each clone was calculated as the sum of male flower production of all ramets belonging to the clone.

\section{Floral synchrony}

Floral synchrony between male and female flowers of different clones was calculated as follows. First, we assessed the temporal pollen dispersal capacity of each clone by examining five ramets per clone every three days from March 6 to April 11. We tapped the male flowers on the five ramets and graded the pollen dispersal capacity of each clone in four classes: (0) pollen not yet ready to shed, (1) small amounts of pollen ready to shed, (2) medium amounts of pollen shed, and (3) considerable amounts of pollen shed. The temporal pollen dispersal capacity on the observation day for each clone was estimated from the average of the pollen dispersal scores of its five ramets. The temporal pollen dispersal capacity was standardized so that the total score over the flowering period be unity.

Next we assessed the temporal reproductive ability of female flowers for each clone. A twig with female flowers (10 to 20 per twig) was covered by a paper bag once every three days from March 12 to April 4. We assumed that there were no phenological differences among ramets belonging to the same clone, since the variation in floral phenology among ramets within clones is usually minor relative to clonal differences in many conifers (JONSSON et al., 1976; GRIFFIN, 1982; EL-KASSABY et al., 1984). All the covering bags were removed in the middle of May when the male flowers finished shedding pollen. Bagged cones were collected at the end of October, and non-bagged (i.e., open-pollinated) cones were also collected randomly as controls. We then carried out a germination test of seeds extracted from the cones in an incubator at $23^{\circ} \mathrm{C}$ for 34 days using 100 seeds per clone with three replicates. The pollination rate of each observation day was defined as the ratio of the germination rate of bagged seeds covered on the observation day to the germination rate of open-pollinated seeds. The reproductive ability of female flower for each clone during the period between two successive observation days can be calculated as the difference in the pollination rate between the two days. This temporal reproductive ability was also standardized so that the total score over the flowering period be unity.

Floral synchrony between two clones can be calculated as degree of overlap between the temporal pollen dispersal capacity of one clone and the temporal reproductive ability of another. That is, the degree of floral synchrony between male flowers of one clone and female flowers of another clone can be calculated as the sum of products between the temporal pollen dispersal capacity and the temporal reproductive ability over all observation days.

\section{Total seed production}

Total seed production of each clone was calculated as follows. First, the amount of cones produced by each ramet was graded in four classes: (0) none, and: (1) light, (2) moderate, and (3) high. Second, all cones were harvested from three randomly selected ramets in each class, and dried. Total weight of seeds extracted from the cones was measured for each ramet. Then, seed production of a single ramet of each specific class was estimated as the average seed weight over the three ramets. Finally, total seed production of each clone was calculated as the sum of seed production of all ramets belonging to the clone. 


\section{DNA extraction}

We collected needles from all clones in the scion garden that provided scions to establish the miniature seed orchard. The total DNA of all constituent clones in the orchard was then extracted from needle tissues using the CTAB method (MurRAY and THOMPson, 1980) or modified CTAB method (TsumurA et al., 1995). The extracted crude DNAs were purified using a Fast DNA kit (BIO 101).

We collected seeds from nine ramets clones (represented by eight clones) to investigate the pollen contamination rate and male reproductive success of each clone in this miniature seed orchard (Figure 1). Seeds were sown on sterilized paper on plastic plates, and DNA was extracted from germinated embryos using the CTAB method (MURRAY and THOMPSON, 1980).

\section{Microsatellite genotyping}

We used six microsatellite markers that showed high stability and polymorphism (Table 1; MORIGUCHI et al., 2003 and TANI et al., 2004) to determine the pollen donors and pollen contamination rates of seeds from nine mother trees. These markers have shown co-dominant segregation in a three-generation pedigree of C. japonica. PCR amplifications were carried out using Model 9600 and 9700 GeneAmp PCR Systems (Applied Biosystems) in mixtures, with a total volume of $10 \mu \mathrm{L}$, containing $20 \mathrm{mM}$ Tris- $\mathrm{HCl}(\mathrm{pH} 8.0), 50 \mathrm{mM} \mathrm{KCl}, 1.5$ $\mathrm{mM}$ of $\mathrm{MgCl}_{2}, 0.16 \mathrm{mM}$ of each dNTP, $0.2 \mu \mathrm{M}$ of each primer, $5 \mathrm{ng}$ of template DNA, and 0.625 units of Taq polymerase (PROMEGA), with the following program: 5 min denaturation at $94^{\circ} \mathrm{C}$; followed by 30-35 cycles of $30 \mathrm{sec}$ denaturation at $94^{\circ} \mathrm{C}, 30 \mathrm{sec}$ annealing at $55-60^{\circ} \mathrm{C}$, and $30 \mathrm{sec}$ extension at $72^{\circ} \mathrm{C}$; with a final extension step of $72^{\circ} \mathrm{C}$ for 5 min. Genotypes of paternal candidate $C$. japonica trees and 100 offspring from each of nine plus trees based on the microsatellite markers were determined using ABI prism 310 and 3100 genetic analyzers (Applied Biosystems).

\section{Data analysis}

From the genotype data for the paternal candidates of the constituent clones, we calculated the number of alleles per locus (NA), polymorphism information content (PIC; BotsteIn et al., 1980), the paternity exclusion probability and multi paternity exclusion probability (WEIR, 1996) for each locus using the G-DIVERSE software developed by Hiroyoshi Iwata (NARC, Tsukuba, Japan).

We determined the pollen donor clones of the seeds that had not originated from pollen contamination or self-fertilization, using the method of MoRIGUCHI et al. (2004). Deviations from equal male reproductive success were evaluated using the $\chi^{2}$ goodness of fit test, as follows. First, we examined the null hypothesis of equal male reproductive success for each ramet to exclude the effect of the number of ramets per clone using the formula $\mathrm{ECV}_{1}$ (see below). Second, we examined the null hypothesis of equal male reproductive success for each ramet to exclude the effect of the difference of total male flower production among clone using the formula $\mathrm{ECV}_{2}$.

$\mathrm{ECV}_{1}=$ (total number of seeds fertilized by plustrees) $\times[$ (number of ramets in $i$-th clone) $/$ (total number of ramets)].

$\mathrm{ECV}_{2}=$ (total number of seeds fertilized by plustrees $) \times[$ (total male flower production of $i$-th clone $) /$ (total male flower production of all clones)].

The observed male reproductive success values were based on the number of seeds contributed by each clone.

To assess the influence of biological traits such as total male flower production and floral synchrony on the male reproductive success of each clone, we performed a multi linear regression analysis, including total male flower production and floral synchrony as independent variables and male reproductive success as a dependent variable, using SPSS ver. 11.5 (SAS Institute Inc., Cary, N.C.).

Table 1. - Microsatellite markers used in this study and their polymorphism.

\begin{tabular}{|c|c|c|c|c|c|}
\hline primer & motif & primer sequence & $\mathrm{NA}^{\mathrm{a}}$ & PIC $^{b}$ & $\mathrm{Q}_{1}^{\mathrm{c}}$ \\
\hline \multirow[t]{2}{*}{ Cjgssr 78} & $(\mathrm{GA})_{21}$ & AAGAAGGCATCCAAGAGTGA & 18 & 0,916 & 0,841 \\
\hline & & ACTGCCGATTAACTGATAGCTC & & & \\
\hline \multirow[t]{2}{*}{ Cs 1525} & $(\mathrm{CA})_{18}$ & ATGAAGTGCCCTTGGTTTGT & 32 & 0,929 & 0,866 \\
\hline & & ATCGCCTCCTCTTTTATCCT & & & \\
\hline \multirow[t]{2}{*}{ Cjgssr 181} & $(\mathrm{GA})_{23}$ & AGAGGGAGGGAGGAATACAT & 42 & 0,950 & 0,905 \\
\hline & & GGCTGAGAGTTTAGGGTTTACA & & & \\
\hline \multirow[t]{2}{*}{ Cjs520 } & $(\mathrm{TG})_{18}$ & TCCCTTTTGGTATTTTACAC & 13 & 0,773 & 0,615 \\
\hline & & ACTCAAATTGCGATAATCTC & & & \\
\hline \multirow[t]{2}{*}{ Cjs 333} & $(\mathrm{GA})_{26}$ & AGGAGATTAGGATGGTGGG & 33 & 0,935 & 0,876 \\
\hline & & GGTTTGCCTCTTCTATGAG & & & \\
\hline \multirow[t]{2}{*}{ Cjgssr 77} & $(\mathrm{CT})_{10}$ & CCTTGTACACTTATTTGTACCT & 29 & 0,855 & 0,748 \\
\hline & & AGGGAGGAGAAATAGACAT & & & \\
\hline
\end{tabular}

\footnotetext{
${ }^{\text {a }}$ Number of allels; total NA $=167$

${ }^{\mathrm{b}}$ Polymorphism information content; average PIC $=0.893$

${ }^{c}$ Multi-paternity exclusion probability $=0.999$
} 
To assess the effect of spatial distance to the mother tree on male reproductive success, we carried out a randomization test as follows. First, we calculated the mean number of seeds of fertilized by the $i$-th of $k$ surrounding clones (where $k=8$, in general). Second, we randomly selected constituent clones of the same number, $k$, and calculated the mean number of seeds fertilized by the $i$-th investigated clone. This randomization process was carried out 10,000 times, generating an empirical distribution of the mean number of seeds under the null hypothesis that male reproductive success does not depend on the distance between maternal and paternal trees. Finally, using the obtained empirical distribution, we calculated the probability of the mean number of seeds fertilized by the $i$-th clone being greater or equal to the number observed, and if the significance level, $P$, of the difference between the randomized and actual distributions was $\leq 0.05$, the alternative hypothesis was accepted.

To assess the relationship between male reproductive success and female reproductive success, we calculated Spearman's $\rho$ rank correlation coefficients between these variables (using SPSS ver. 11.5; SAS Institute Inc., Cary, N.C.) for all constituent clones.

\section{Results and Discussion}

\section{Microsatellite markers}

For paternity analysis markers are required that can provide high multi-paternity exclusion probabilities (WEIR, 1996). The six microsatellite markers we used here had sufficient polymorphism for this purpose, yielding a multi-paternity exclusion probability of 0.999 (Table 1), and thus sufficient resolution to determine pollen donors in the seed orchard.

\section{Differences in male reproductive success}

Airborne dispersal of $C$. japonica pollen had begun by 7 March at each observation point and increased rapidly from 11 March. The highest peaks were recorded on 19 and 28 March (Figure 2). Little airborne pollen was recorded after the end of April. The pollen captured at the two monitoring points (one inside and one outside the orchard) showed similar dispersal patterns.

We were able to determine a paternal clone for each seed after excluding seeds originating from contamination (i.e., fertilization by pollen from outside the orchard) $(38.7 \%)$ and self-fertilization (1.7\%). The $\chi^{2}$ test for the goodness of fit to the null hypothesis of equal male reproductive success of each clone showed that the level of male reproductive success, in terms of their contributions to seed production by the constituent clones, differed significantly ( $p<0.001$ in both cases). Although in both cases the departure from the expectation on equal male reproductive success were highly significant, the $\chi^{2}$ value was smaller in the case considering the total male flower production of each clone than that in the case considering the total number of ramets of each clone. This indicates that total male flower production of each clone may be more important than total number of ramets of each clone when we will equalize the contribution of each clone as a pollen donor. Eight clones (nos. 5, $6,10,26,31,52,54$, and 57) showed no male reproductive success at all. The clone with the highest male reproductive success was clone 53, which fertilized $9.8 \%$ of the examined seeds (Figure 3). The five clones with the highest male reproductive successes (nos. 53, 3, 58, 71 , and 11) collectively accounted for about $30 \%$ of the paternity of all assessed seeds that did not originate from fertilization by contaminating pollen. Similar results have been found in seed orchards of other conifer species, such as Pinus contorta Dougl., Pinus thunbergii Parl. and Pseudotsuga menzeisii Franco (STOEHR et al., 1998; Gото et al., 2002; STOEHR and NewTon, 2002). However, the male reproductive success of each constituent clone should ideally be roughly equal to ensure high genetic diversity amongst the resulting seeds and to help protect the progeny against disease and environmental changes (ZHU et al., 2000; BURDON, 2001).

\section{Relationships between male reproductive success and biological traits}

The total male flower production of the clones was strongly associated with their male reproductive suc-

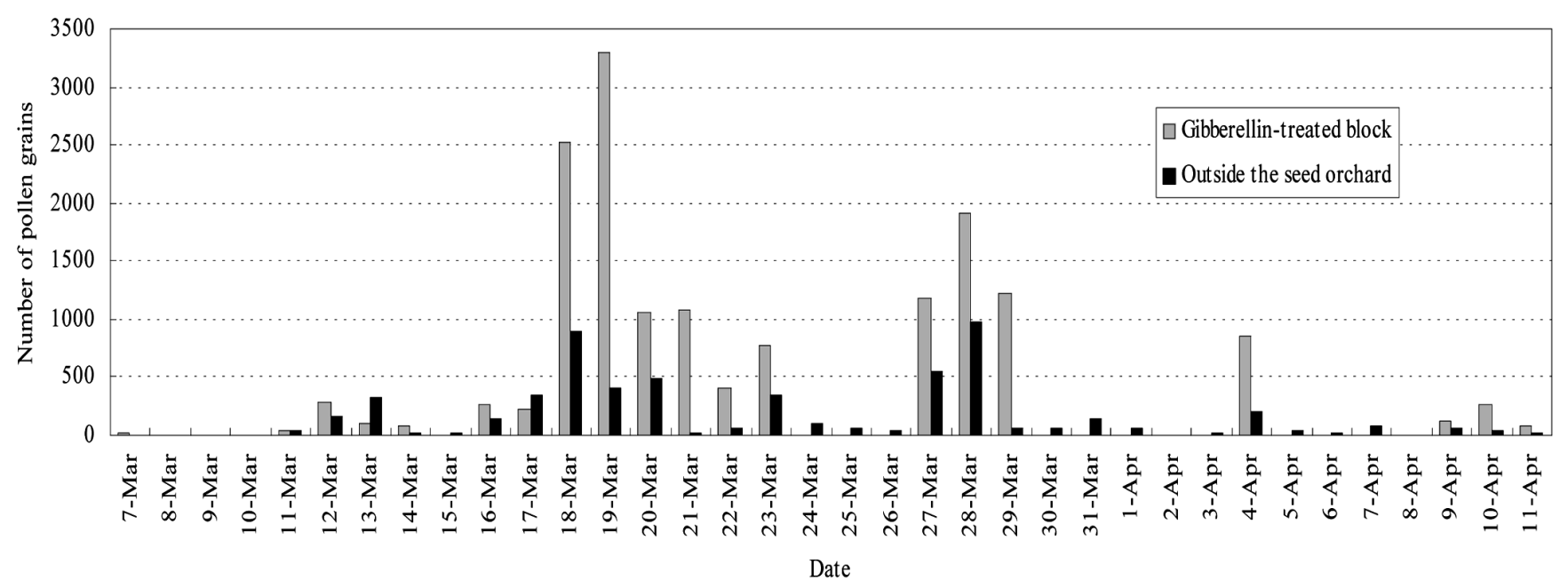

Figure 2. - Airborne pollen counts in the gibberellin-treated block and outside the seed orchard. 


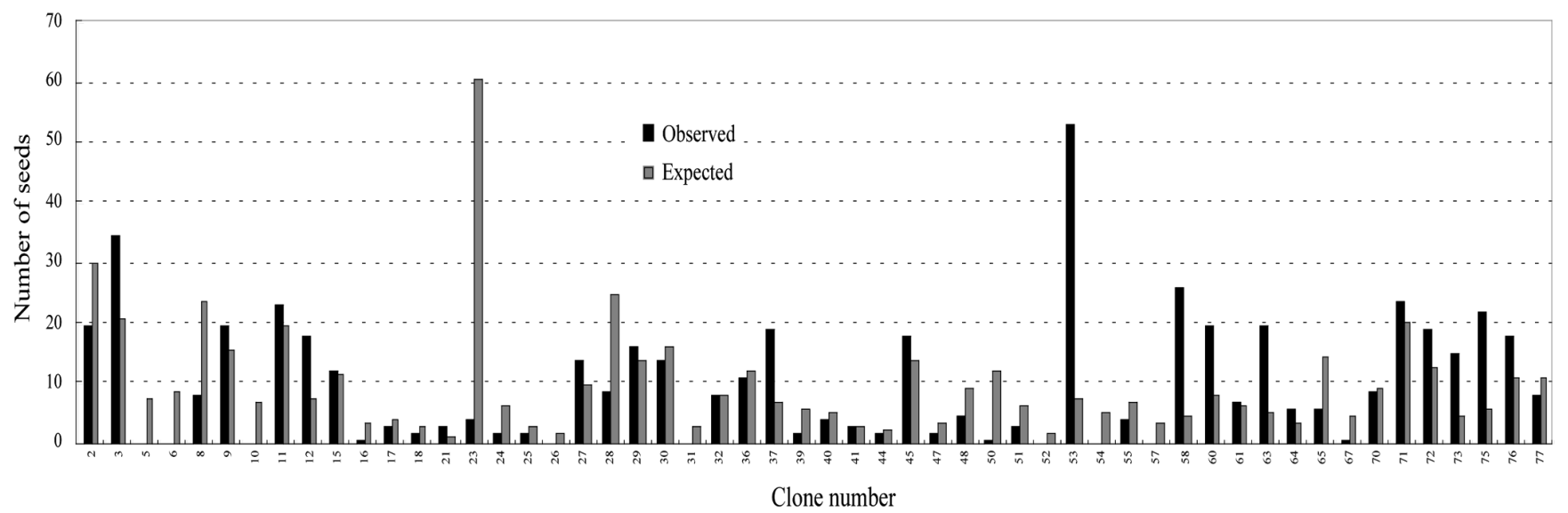

Figure 3. - Observed (solid bars) and expected male reproductive success (open bars) of each clone. The $\mathrm{ECV}_{2}$ values in text were used as expected male reproductive success.

cesses (Figure 4; Table 2), but there was no clear relationship between male reproductive success and the floral synchrony (Figure 5). The multilinear regression model we derived accounted for ca. $15 \%$ of the variance in the male reproductive success of the clones. The coefficient of regression was significant at the $0.5 \%$ probability level for total male flower production, but non-significant for floral synchrony (Table 2). A single linear regression of male reproductive success on total male

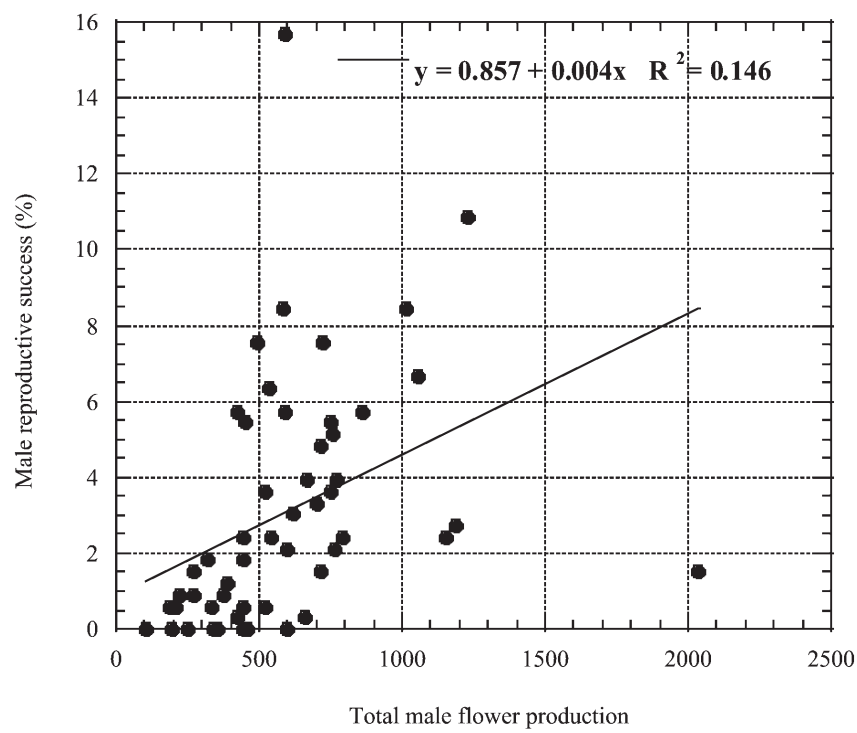

Figure 4. - The relationship between male reproductive success and total male flower production. The male reproductive success of each clone is represented by the proportion of seeds originating from fertilization by its pollen (relative to all seeds except those originating from fertilization by contaminating pollen). flower production showed a significant positive slope $(\mathrm{P}<0.005$; Figure 4). This finding is consistent with previous reports that the total number of male cones correlates with male reproductive success in Picea glauca Voss (Schoen and Stewart, 1986), Pseudotsuga menziesii Franco (BURCZYK and PRAT, 1997) and Pinus thunbergii Parl. (GoTo et al., 2005). In our study, there was a ca. 20-fold difference in pollen production between the clones that produced the most and least pollen. Similarly, KUSABA (1985) reported that the amount of male flower production differed 100 -fold between clones in another C. japonica seed orchard. Thus, the influence of the differences in total male flower production among clones on male reproductive success might be unexpectedly large in conifers.

ERICKSON and ADAMS (1989) suggested that both relative male flower production and floral overlap could strongly influence inter-mating patterns amongst seed orchard clones, and Gото et al. (2002) have shown that a lack of flowering phenology overlap with other clones can inhibit male reproductive success. However, in our study, there was no apparent relationship between male reproductive success and floral synchrony (Figure 5; Table 2). In C. japonica, pollen grains are pulled into the micropyle rapidly after capture by the pollination droplet (the fluid in the canal). We investigated the flowering period of female flowers using paper bags, because it is impractical to observe pollination droplets directly. The data we gathered in this manner show that the male reproductive success of each clone was not significantly influenced by the floral synchrony per se, but it was significantly affected by the density of their pollengrains in the air at the time that the pollination droplets were extruded. Therefore, it may be difficult to detect

Table 2. - Results of the multilinear regression, including male reproductive success as a dependent variable, and total male flower production and floral synchrony as independent variables.

\begin{tabular}{cccccc}
\hline Variables & $R^{2}$ & Adjusted $R^{2}$ & Standardized coefficient & $t$ & $P$ \\
\hline Constant & 0,147 & 0,113 & - & 0,806 & 0,424 \\
male flower production & & & 0,382 & 2,949 & $<0.005$ \\
floral synchrony & & & $-0,025$ & $-0,195$ & 0,846 \\
\hline
\end{tabular}




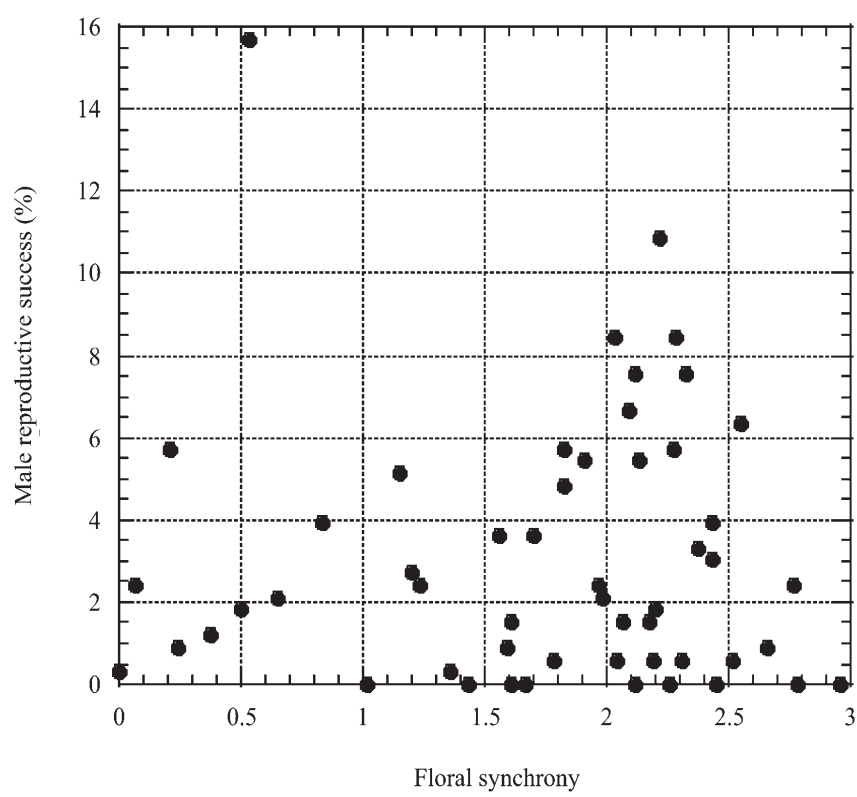

Figure 5. - The relationship between male reproductive success and floral synchrony. The male reproductive success of each clone is represented by the proportion of seeds originating from fertilization by its pollen (relative to all seeds except those originating from fertilization by contaminating pollen).

effects of floral synchrony due to the stronger effect of total male flower production.

The low $R^{2}$ values obtained in the regression analysis imply that factors other than male flower production and floral synchrony influenced male reproductive success (Table 2). Male reproductive success depends not only on flowering traits, such as male flower production and floral synchrony, but also on inter-tree distances and traits of the pollen grains, such as germination vigor and time, pollen growth rate and selective fertilization (PFAHLER, 1975). In this study, the substantial male reproductive success of clone 53 was mainly due to its high contribution to seed production in clone 6 (accounting for about $64 \%$ of its total fertilizations). The floral synchrony period between these clones is not very long, so other factors such as pollen competition may also influence male reproductive success (STOEHR et al., 1999; NikKANEN et al., 2000; ARONEN et al., 2002). Further study is required to assess this possibility.

Table 3. - Significance of the distance to each of the mother trees considered in the randomization test.

\begin{tabular}{cc}
\hline Mother tree & $P$ \\
\hline BG & 0,329 \\
AP & $<0.01$ \\
AU & $<0.01$ \\
AM & 0,696 \\
AH & 0,112 \\
AO & $<0.001$ \\
AA & 0,159 \\
AI & $<0.01$ \\
AX & $<0.01$ \\
\hline
\end{tabular}

Effect of spatial distance to mother trees on male reproductive success

In the randomization test, we detected significant distance effects on male reproductive success in five of the nine investigated trees (Table 3), implying that male reproductive success was related to the distance between the mother trees and pollen donors. This distance may slightly influence male reproductive success, although the observed tendency was not strong. SHEN et al. (1981) found that as much as $31 \%$ of the fertilizing pollen could be received from neighboring trees when the wind direction and flowering times were favorable. ERICKSON and ADAMs (1989) also suggested that the distance between mother trees and pollen donors is an important factor for mating success when the combined effects of floral overlap and relative male flower production of potential male parents is high. Our results are consistent with these reports.

\section{Seed orchard improvement}

The results of the present study indicate that total male flower production strongly affects male reproductive success and the inter-tree distance also has some effect. The distance effects may be balanced out when all the seeds from all ramets representing the same clone are considered, because seed orchards are generally designed to promote random mating. To reduce inequalities in male reproductive success in seed orchards, we should pay more attention to the total male flower production of each clone. However, total reproductive success includes not only male reproductive success, but also female reproductive success. We investigated the relationship between male reproductive and female reproductive success, but found no correlation between them (Figure 6, Spearman $\rho=-0.79, P=0.568$ ), sug-

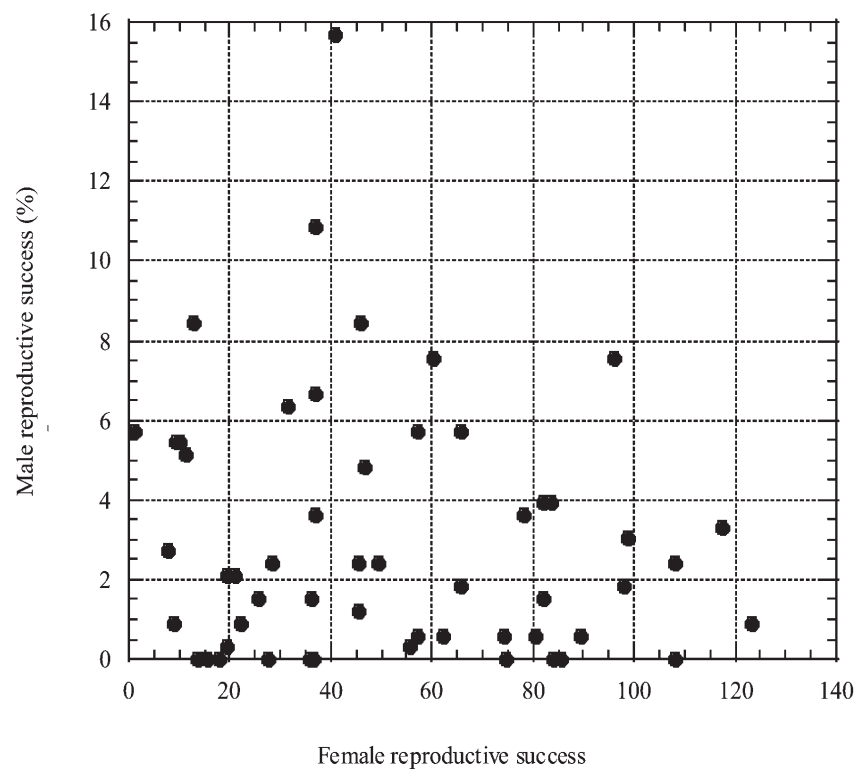

Figure 6. - The relationship between male reproductive success and female reproductive success. The male reproductive success of each clone is represented by the proportion of seeds originating from fertilization by its pollen (relative to all seeds except those originating from fertilization by contaminating pollen). Female reproductive success is represented by the total seed production of each clone. 
gesting that we should concentrate on equalizing male flower production and/or synchronizing floral phenology between clones in seed orchards. To reduce the variations in reproductive success we could harvest equal numbers of seeds from each of the clones, or adjust the numbers of the various clones to equalize male flower production, if the labor costs are not too high. The information from our study should facilitate the future improvement of $C$. japonica seed orchards.

\section{Acknowledgements}

The authors thank S. GoTo for kind advice and valuable suggestions for an early version of it. We also thank T. Sugaya, Y. Takeuchi, Y. Naito, T. TAKahashi, E. Yoshi and other members of Professor Taira's lab in Niigata University for their help in seed collection. This work was supported by grants from Pioneer Special Studies of the Ministry and Agriculture, Fishery and Forestry of Japan and Research Fellowships of the Japan Society for the Promotion of Science for Young Scientists and the Japan Society for the Promotion of Science, Grant-in-Aid for Scientific Research (B) no. 16380112.

\section{References}

Adams, W. T., V. D. Hipkins, J. BurczyK and W. K. RanDALL (1997): Pollen contamination trends in a maturing Douglas-fir seed orchard. Can J For Res 27: 131-134.

Aronen, T., T. Nikkanen, A. Harju, H. Timmonen and H. HÄGGMAN (2002): Pollen competition and seed-siring success in Picea abies. Theor Appl Genet 104: 638-642.

Botstein, D., R. L. White, M. Skolnick and R. W. Davis (1980): Construction of a genetic linkage map in man using restriction fragment length polymorphisms. Am J Hum Genet 32: 314-331.

BuRCZYK, J. and D. PART (1997): Male reproductive success in Psedotsuga menziesii (Mirb.) Franco: the effects of spatial structure and flowering characteristics. Heredity 79: 638-647.

BuRDON, R. D. (2001): Genetic diversity and disease resistance: some considerations for research, breeding, and deployment. Can J For Res 31: 596-606.

DuRHAM, O. C. (1946): The volumetric incidence of atmospheric allergens IV. A proposed standard method of gravity sampling, counting and volumetric interpolation of results. J. Allergy 17: 79-86.

El-Kassaby, Y. A., A. M. Fashler and O. SzikLai (1984): Reproductive phenology and its impact on genetically improved seed production in a Douglas-fir seed orchard. Silvae Genet 33: 120-125.

ERICKSON, V. J. and W. T. ADAMs (1989): Mating success in a coastal Douglas-fir seed orchard as affected by distance and floral phenology. Can J For Res 19: 1248-1255.

FRIEDMANN, S. T. and W. T. AdAMS (1985): Estimation of gene flow into two seed orchards of loblolly pine (Pinus taeda L.). Theor Appl Genet 69: 609-615.

Goto, S., F. MiYAhARA and Y. IDE (2002): Monitoring male reproductive success in a Japanese black pine clonal seed orchard with RAPD markers. Can J For Res 32 983-988.

Goto, S., A. Watanabe, F. Miyahara and Y. Mori (2005): Reproductive success of pollen derived from selected and non-selected sources and its impact on the performance of crops in a nematode-resistant Japanese black pine seed orchard. Silvae Genet. 54: 69-76.
GRIFFIN, A. R. (1982): Clonal variation in radiata pine seed orchards. I. Some flowering, cone and seed production traits. Aust For Res 12: 295-302.

KusabA, T. (1985): The characteristics of flowering and seed production of clones in the Cryptomeria japonica D. Don seed orchard. J Ibaraki For Prod Res Cent 18: 25-42. (in Japanese).

Jonsson, A., J. EKBERG and G. ERIKSSON (1976): Flowering in a seed orchard of Pinus sylvestris L. Stud For Suec 135: 5-38.

Moriguchi, Y., H. Iwata, T. Ihara, K. Yoshimura, H. TAIRA and Y. TSUmuRA (2003): Development and characterization of microsatellite markers for Cryptomeria japonica D. Don. Theor Appl Genet 106: 751-758.

Moriguchi, Y., H. TAIRA, N. TANi and Y. Tsumura (2004): Variation of paternal contribution in a seed orchard of Cryptomeria japonica determined using microsatellite markers. Can J For Res 34: 1683-1690.

Moriguchi, Y., N. TANi, S. Itoo, F. Kanehira, K. TANaka, H. Yomogida, H. TAIRA and Y. Tsumura (2005): Gene flow and mating system in five Cryptomeria japonica D. Don seed orchards as revealed by analysis of microsatellite markers. Tree Genet Genomes 1: 174-183.

MurRAY, M. and W. F. THOMPSON (1980): Rapid isolation of high molecular weight plant DNA. Nucleic Acids Res 8: 4321-4325.

Nikkanen, T., T. Aronen, H. HägGman and M. VenäläINEN (2000): Variation in pollen viability among Picea abies genotypes - potential for unequal paternal success. Theor Appl Genet 101: 511-518.

Pakkanen, A., T. Nikkanen and P. Pulkkinen (2000): Annual variation in pollen contamination and outcrossing in a Picea abies seed orchard. Scand J For Res 15: 399-404.

PfAHLER, P. L. (1975): Factors affecting male transmission in maize (Zea mays L.), pp 115-124 in Gamete competition in plants and animals, edited by D. L. MuLCAHY, North Holland, Amsterdam.

RitLAND, K. and Y. A. El-Kassaby (1985): The nature of inbreeding in a seed orchard of Douglas fir as shown by an efficient multilocus model. Theor Appl Genet 71: 375-384.

Rudin, D., O. Muona and R. YAZDANi (1986): Comparison of the mating system of Pinus sylvestris in natural stands and seed orchards. Hereditas 104: 15-19.

SHEN, H. H., D. RUDIN and D. LINDGREN (1981): Study of the pollination pattern in a Scots pine seed orchard by means of isozyme analysis. Silvae Genet 30: 7-15.

Schoen, D. J. and S. C. STEWART (1986): Variation in male reproductive investment and male reproductive success in white spruce. Evolution 40: 1109-1120.

Stoehr, M. U., B. L. Orvar, J. R. GaWley, J. E. Webber and C. H. NEwTon (1998): Application of a chloroplast DNA marker in seed orchard management evaluations of Douglas-fir. Can J For Res 28: 187-195.

Stoehr, M. U., M. C. Mullen, D. L. S. Harrison and J. E. WeBBER (1999): Evaluating pollen competition in Douglas-fir using a chloroplast DNA marker. For Genet 6: 49-53.

Stoehr, M. U. and C. H. NewTon (2002): Evaluation of mating dynamics in a lodgepole pine seed orchard using chloroplast DNA markers. Can J For Res 32: 469-476.

TANI, N., T. TAKahashi, T. UJino-Ihara, H. Iwata, K. Yoshimura and Y. Tsumura (2004): Development and characteristics of microsatellite markers for sugi (Cryptomeria japonica D. Don) from microsatellite enriched libraries. Ann For Sci 61: 569-575. 
Tsumura, Y., K. Yoshimura, N. Tomaru and K. OhBA (1995): Molecular phylogeny of conifers using RFLP analysis of PCR-amplified specific chloroplast genes. Theor Appl Genet 91: 1222-1236.

WeIR, B. S. (1996): Genetic Data Analysis II. Sinauer Assoc, Sunderland, Mass.

WheELER, N. C. and K. S. JECH (1992): The use of electrophoretic markers in seed orchard research. New Forests 6: 311-328.
YAZDANI, R. and D. LINDGREN (1991): Variation of pollen contamination in a Scots pine seed orchard. Silvae Genet 40: 243-246.

Zhu, Y., H. Chen, J. FAn, Y. Wang, Y. Li, J. Chen, J. X. Fan, S. Yang, L. Hu, H. Leung, T. W. Mew, P. S. Teng, Z. WANG and C. C. MUNDT (2000): Genetic diversity and disease control in rice. Nature 406: 718-722.

\title{
Genetic Relationships among Schizolobium parahybum (Vell.) Blake (Leguminosae) Ecotypes from Ecuador and other Countries
}

\author{
By H. F. Canchignia-Martínez ${ }^{1)}$, S. Hernández-Delgado ${ }^{2)}$, M. GonzÁlez-Paz ${ }^{2)}$, E. Motte ${ }^{3)}$ and N. MaYek-PÉREz ${ }^{2), *)}$
}

(Received $8^{\text {th }}$ May 2006)

\begin{abstract}
Fifteen ecotypes of Schizolobium parahybum (Vell.) Blake collected in Ecuador (9), Brazil (3), Bolivia (1) Costa Rica (1), and Peru (1) were analyzed using Random Amplified Polymorphic DNA (RAPDs), Amplified Fragment Length Polymorphisms (AFLPs) and microsatellites (SSRs) in order to determine their genetic relationships and diversity patterns among ecotypes and to identify the origin of cultivated germplasm in Ecuador. Although AFLP markers were the most informative technique based on amplified products, SSRs clearly differentiated the ecotypes of Ecuador based on their geographical origin or genetic status into two groups: commercial ecotypes growing at western Ecuador very similar to the ecotype from Costa Rica, and native germplasm from eastern Ecuador and ecotypes from Brazil, Peru and Bolivia.
\end{abstract}

Key words: AFLP, genetic relationships, DNA-fingerprinting, RAPD, Schizolobium parahybum (Vell.) Blake, SSR.

\section{Introduction}

Forestry industry for wood production of Ecuador extensively exploits Schizolobium parahybum (Vell.) Blake ("pachaco", "guanacastle" or "palo de picho"). This species is largely distributed through America due it shows good adaptation to variable climate conditions and has great possibilities to continue its exploitation for wood production and other uses. Farmers from

\footnotetext{
1) Universidad Técnica Estatal de Quevedo. Avenida Quito km 1 Vía Santo Domingo. Quevedo, Los Ríos, Ecuador.

2) Centro de Biotecnología Genómica-Instituto Politécnico Nacional. Blvd. del Maestro esq. Elías Piña s/n, Col. Narciso Mendoza, 88710, Reynosa, México. Tel/Fax (899) 9243627.

3) Programa de Biotecnología - Universidad de Guayaquil. Av. Kennedy y Delta, Ciudadela Universitaria, A. Postal 471, Guayaquil, Ecuador.

*) Corresponding author: E-mail: nmayek@ipn.mx.
}

Ecuador are interested to establish orchards which show fast growth and the best wood quality for production of cellulose (MontenEgro, 1987). In 1950, S. parahybum was introduced to Quevedo, Ecuador by the Experimental Laboratory "Pichilingue" of the Instituto Nacional de Investigaciones Agrícolas y Pecuarias (INIAP). Although no data are available about the origin of the introduced germplasm, it has been assumed that it originated from Costa Rica. Therefore, no evidence is known about the origin of the most of commercial plantations in Ecuador, from Costa Rica or native germplasm. In Ecuador, $S$. parahybum is commonly propagated by seeds but no plant or seed pre-selection is done for the establishment of orchards and this fact has increased the genetic variability on commercial and native plantations (TIPAN, 1982).

The knowledge of genetic diversity and the relationships among genotypes will be important for the development of appropriate strategies for the in situ conservation of natural woods and the regeneration of partially logged forests of $S$. parahybum in Ecuador. This information can also serve as a baseline for determining whether genetic diversity has been lost through the sampling or conservation involving ex situ propagation, since those facts have been done in germplasm from Ecuador for plant improvement. Genetic diversity characterizations will be useful for planning a breeding strategy for commercial purposes. Genetic diversity of $S$. parahybum could be characterized based on morphological traits or using molecular markers which detect variation at the DNA sequence level. In particular, DNA-based polymorphisms are a powerful tool for assess genetic similarity between natural and breed genotypes.

The PCR-based techniques provide a representative sample of the genome and a virtually unlimited number 